\title{
Effects of puberty and gonadotropins on the molecular events controlling meiotic resumption of mouse oocytes
}

\author{
Dong Han, Xin-Yan Cao, Hui-Li Wang, Jing-Jing Li, Yan-Bo Wang and Jing-He Tan \\ Laboratory for Animal Reproduction and Embryology, College of Animal Science and Veterinary Medicine, Shandong \\ Agricultural University, Tai-an City 271018, Shandong Province, People's Republic of China
}

Correspondence should be addressed to J-H Tan; Email: tanjh@sdau.edu.cn

\begin{abstract}
Although studies suggest that the low competence of oocytes from prepubertal animals is due to their insufficient cytoplasmic maturation and that FSH improves oocyte maturation possibly by retarding meiotic progression and allowing more time for cytoplasmic maturation, the mechanisms by which puberty and gonadotropins regulate meiotic progression require additional detailed studies. For the first time, we observed that while meiotic progression was significantly slower, the maturation-promoting factor (MPF) activity of oocytes was significantly higher in prepubertal than in adult mice. To resolve this contradiction, we specified the molecules regulating the MPF activity and their localization during oocyte maturation in prepubertal and adult mice primed with or without gonadotropins. Our tests using corresponding enzyme regulators suggested that while activities of protein kinase A were unaffected, the activity of adenylate cyclase (ADCY) and phosphodiesterase increased while cell division cycle 2 homolog A (CDC2A) decreased significantly after puberty. While most of the adult oocytes had CDC2A protein concentrated in the germinal vesicle (GV) region, the majority of prepubertal oocytes showed no nuclear concentration of CDC2A. Maximally priming mice with equine chorionic gonadotropin brought the above parameters of prepubertal oocytes close to those in adult oocytes. Together, the results suggest that puberty and gonadotropin control oocyte meiotic progression mainly by regulating the ADCY activity and the concentration of the activated MPF toward the GV region. Reproduction (2010) 139 959-969
\end{abstract}

\section{Introduction}

Puberty is the transition from a sexually immature state to one of full reproductive activity with the production of mature gametes. Puberty in mammals has been considered a variation on the metamorphic scheme in amphibians and insects, and has therefore been an important topic in developmental biology and endocrinology. Studies on puberty-associated changes in bodily form, sexual organs and activities, and endocrinology indicate that puberty is a hormonally controlled reactivation of development leading to sexual maturity and changes in bodily form and physiology (Gilbert 1985). However, puberty-associated molecular changes within the germ cell are largely unknown.

Although oocytes obtained from prepubertal animals have produced viable offspring after in vitro maturation and IVF (Revel et al. 1995, O'Brien et al. 1997, Khatir et al. 1998a, Ptak et al. 1999), the developmental competence of these embryos was lower than that of embryos produced from adult animals (Seidel et al. 1971, Pinkert et al. 1989, Eppig et al. 1992, Revel et al. 1995, Damiani et al. 1996, Khatir et al. 1996, O'Brien et al. 1996, 1997, Ledda et al. 1997, Izquierdo et al. 1999, Wu et al. 2007). In vitro matured oocytes of prepubertal bovine showed abnormal chromatin microtubule configurations and protein synthesis (Damiani et al. 1996, Gandolfi et al. 1998, Khatir et al. 1998b). In addition, increased parthenogenetic activation and polyspermy have been observed in lamb compared with ewe oocytes (Ledda et al. 1997). These observations reveal incomplete maturation or cytoplasmic deficiencies of the oocytes obtained from prepubertal animals. However, the causes for the insufficient maturation of prepubertal oocytes are poorly understood.

Increasing evidence demonstrates that oocyte quality depends on the events before germinal vesicle breakdown (GVBD), suggesting that the oocyte must accumulate the appropriate information for meiotic resumption, fertilization, and embryo development before chromosome condensation (Sirard et al. 2007). Thus, in vivo, oocytes acquire cytoplasmic maturity after a long series of preparatory processes involving transcription and translation of transcripts during the meiotic prophase (Gosden et al. 1997, Hyttel et al. 1997), whereas in vitro, a premature meiotic resumption without adequate cytoplasmic maturation is induced by transfer of oocytes from follicles into culture medium. Therefore, the developmental capacity of in vitro 
matured oocytes is markedly lower than that of their in vivo matured counterparts (Sirard \& Blondin 1996, Trounson et al. 1998). It is known that FSH is essential for full maturation of oocytes both in vivo and in vitro (Sirard et al. 2007), and priming prepubertal animals with gonadotropin improved their oocyte quality significantly (Koeman et al. 2003, Wu et al. 2007). Furthermore, FSH retarded oocyte nuclear maturation in vitro, thereby enhancing subsequent developmental competence by allowing more time for cytoplasmic maturation (Armstrong et al. 1991).

Meiotic progression is regulated by the activity of the maturation-promoting factor (MPF), which is a complex composed of a catalytic cell division cycle 2 homolog A $(\mathrm{CDC} 2 \mathrm{~A})$ and the cyclin B regulatory subunit (Han \& Conti 2006). High cAMP levels in the oocyte maintain protein kinase $A$ (PRKA) in an active state, and the activated PRKA maintains the MPF in an inactive state by phosphorylating the CDC25 and WEE1 kinase. Oocytes remain in a GV state as long as the MPF is inactive, and the activation of MPF triggers GVBD. Gonadotropins interact with their receptors on the membrane of granulosa cells or oocytes to activate adenylate cyclase (ADCY; Kolena \& Channing 1972, Hunzicker-Dunn \& Birnbaumer 1976, Olsiewski \& Beers 1983). The hormone-receptor binding causes a conformation change in the receptor, allowing its interaction with the $G$ protein, and thus, the hormonal signal is transduced from the receptor to ADCY to catalyze the transformation of ATP into cAMP (Gilman 1990).

Therefore, it is deduced that compared with adult oocytes, the prepubertal oocytes would have higher MPF activities and thereby a faster meiotic progression which could explain their insufficient cytoplasmic maturation. However, the MPF activities in calf and lamb oocytes were found to be lower than in cow and ewe oocytes (Ledda et al. 2001, Salamone et al. 2001), and nuclear maturation of calf oocytes went slower than that of cow oocytes (Khatir et al. 1998b). Furthermore, although it was shown that gonadotropins activated ADCY and thereby increased the production of cAMP in granulosa cells (Hamberger et al. 1978, Lindsey \& Channing 1979), the signaling events between puberty/gonadotropins and the MPF activity have yet to be studied in detail. In this study, a contradictory phenomenon was first observed that the prepubertal mouse oocytes showed a significantly slower meiotic progression while having a much higher MPF activity than adult oocytes. A hypothesis for this contradictory situation was then proposed that the prepubertal oocytes would have a high activity of certain signaling molecules regulating the MPF activity, but the molecule could not function properly due to inappropriate distribution. The hypothesis was finally tested by specifying the molecule in the signaling pathway leading to MPF activation and by examining its localization during oocyte maturation.

\section{Results}

\section{Effects of puberty and gonadotropin stimulation on meiotic progression and MPF activities of mouse oocytes}

During in vitro maturation, meiotic progression of oocytes from unstimulated and 3-IU equine chorionic gonadotropin (eCG)-primed prepubertal mice was similar but was significantly $(P<0.05)$ slower than that of oocytes from the adult and 10-IU eCG-primed prepubertal mice (Fig. 1). However, lengths of prometaphase I (pMI), metaphase I (MI), and anaphase/ telophase I (A/TI) were similar $(P>0.05)$ among different oocytes. During maturation in vivo, the GV stage of oocytes from 3-IU eCG-primed prepubertal mice $(4.3 \mathrm{~h})$ lasted much $(P<0.05)$ longer than that of oocytes from the adult and 10-IU eCG-primed prepubertal mice $(3.1 \mathrm{~h})$. Although the time for 3-IU eCG-primed prepubertal oocytes to enter the metaphase II (MII) stage was similar $(P>0.05)$ between in vivo (10.7 h post human chorionic gonadotropin (hCG)) and in vitro (10.4 h of culture), the duration of the GV stage lasted much longer in vivo $(4.3 \mathrm{~h})$ than in vitro $(1.7 \mathrm{~h})$.

Oocytes maturing in vivo or in vitro were assayed for histone $\mathrm{H} 1$ kinase activity when over $70 \%$ of them had been found at each stage of maturation. Oocytes at the GV stage were assayed at $46 \mathrm{~h}$ post eCG injection. Furthermore, only oocytes showing the desired chromatin configurations following Hoechst 33342 staining

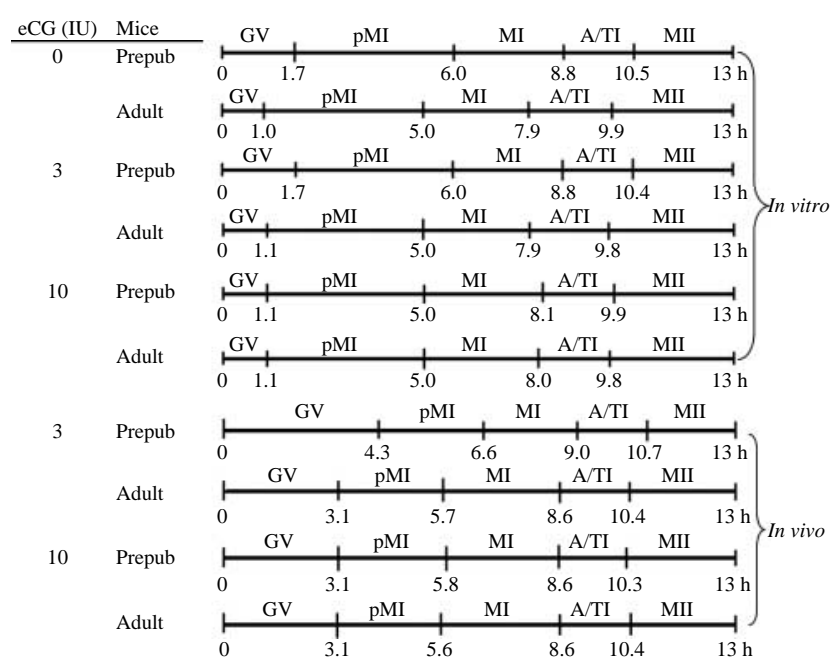

Figure 1 The mean time (h) that an oocyte spent at each stage of nuclear progression during maturation in vitro or in vivo. To observe meiotic progression in vitro, the COCs at the GV stage from prepubertal or adult mice that had been primed with different dosages of eCG were cultured in maturation medium for different times before examination for meiotic progression. To observe meiotic progression in vivo, prepubertal and adult mice were superovulated with 3- or 10-IU eCG followed by 10-IU hCG, and oocytes were collected at different times post hCG injection. The calculation was done according to Sirard et al. (1989), and was based on data collected at $0,1,3,5,7,9,11$, and $13 \mathrm{~h}$ after the onset of culture or hCG injection. 

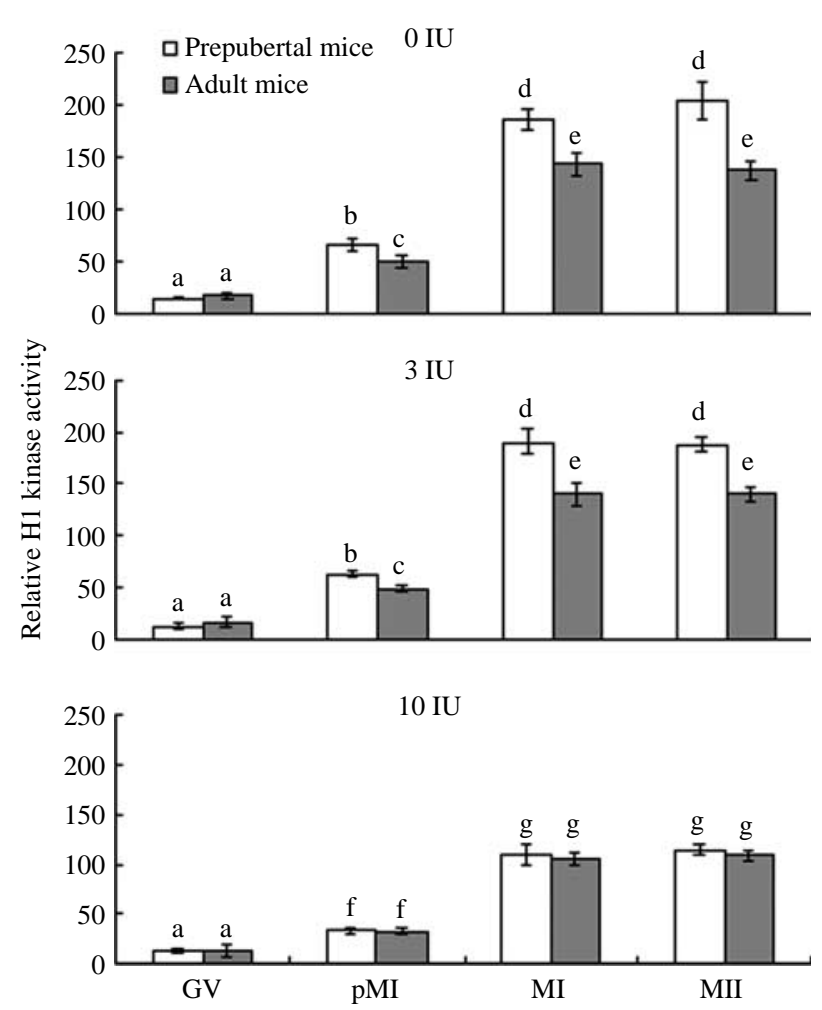

Figure 2 Relative histone $\mathrm{H} 1$ kinase activities of mouse oocytes during maturation in vitro. Oocytes collected from mice that had been primed with 0 -, 3- or 10-IU eCG were cultured in vitro, and histone $\mathrm{H} 1$ kinase activities were assayed separately at the GV, pMI, MI, and MII stages. The histone $\mathrm{H} 1$ activity values of in vivo matured oocytes collected $11 \mathrm{~h}$ post hCG injection from the 3-IU eCG-primed prepubertal mice were arbitrarily set as $100 \%$, and the other values were expressed relative to this activity. Means without a common letter above their bars differ $(P<0.05)$ within stages of meiotic progression.

were assayed. The histone $\mathrm{H} 1$ kinase activity was low at the GV stage (Fig. 2). During maturation in vitro, histone $\mathrm{H} 1$ kinase activities at the $\mathrm{pMI}, \mathrm{MI}$, and MII stages were significantly higher in prepubertal than in adult oocytes when mice were unstimulated or stimulated with 3-IU eCG. When mice were primed with 10-IU eCG, however, the kinase activity did not differ between prepubertal and adult oocytes at any maturation stage. Changes in the kinase activity during maturation in vivo followed the same pattern as during maturation in vitro, but overall, it was much higher in vitro than in vivo. Thus, while the in vivo matured oocytes from 3-IU eCG-primed prepubertal mice showed a histone $\mathrm{H} 1$ kinase activity of $100 \%$, their in vitro matured counterparts showed a kinase activity of $188 \%$ (data not shown).

When GV karyoplasts prepared from adult mice $46 \mathrm{~h}$ after eCG injection (10 IU/mouse) were electrically fused with in vitro matured oocytes from unstimulated prepubertal or adult mice, the fusion-GVBD interval was significantly shorter in prepubertal oocytes (15.0 $\pm 1.0 \mathrm{~min}, n=31)$ than in adult oocytes $(19.3 \pm 1.0 \mathrm{~min}$, $n=27)$. When oocytes from unstimulated animals were in vitro matured for $14 \mathrm{~h}$ and treated with $\mathrm{SrCl}_{2}$ for activation, the activation rate of prepubertal oocytes $(57.2 \pm 5.2, n=149)$ was significantly lower than that of adult oocytes $(73.9 \pm 6.4, n=104)$.

How did the prepubertal mouse oocytes show a significantly slower meiotic progression while having much higher MPF activities than adult oocytes? Our hypothesis for this contradictory situation was that the prepubertal oocytes would have a higher activity of certain signaling molecules regulating the MPF activity, but although activated, the molecule could not function properly due to inappropriate distribution. The following experiments were conducted to test this hypothesis by specifying the signaling molecule and by observing its distribution during oocyte maturation.

\section{Effects of puberty and gonadotropin stimulation on signaling molecules regulating the MPF activity of mouse oocytes}

\section{The ADCY activities}

To test the ADCYactivities, oocytes were cultured for $4 \mathrm{~h}$ in maturation medium supplemented with different concentrations of forskolin before examination for GVBD. In unstimulated and 3-IU eCG-primed mice, while $25 \mu \mathrm{M}$ forskolin prevented GVBD of adult cumulus-oocyte complexes (COCs), the GVBD in prepubertal COCs was not inhibited until forskolin increased to $100 \mu \mathrm{M}$ (Table 1). In mice primed with 10-IU eCG, however, the efficient concentration for GVBD inhibition of COCs halved to 12.5 and $50 \mu \mathrm{M}$ in adult and prepubertal oocytes respectively. Forskolin could not inhibit GVBD of prepubertal denuded oocytes (DOs), but inhibited adult DOs when applied at $200 \mu \mathrm{M}$.

Capillary electrophoresis performed on oocytes at the GV stage immediately (within $10 \mathrm{~min}$ ) after collection from prepubertal or adult mice (Fig. 3A) showed that the relative level of cAMP was significantly higher in adult than in prepubertal oocytes and in COCs than in DOs from unstimulated animals. Gonadotropin stimulation increased the cAMP level significantly in both prepubertal and adult oocytes. Capillary electrophoresis performed on COCs from unstimulated mice at 0 (immediately after oocyte collection), 30, and $60 \mathrm{~min}$ of culture in maturation medium (Fig. 3B) indicated that while the CAMP level declined significantly prior to GVBD (30 min of culture) in both prepubertal and adult oocytes, the cAMP level of adult oocytes was still significantly higher than that of prepubertal oocytes. The cAMP levels dropped further by $60 \mathrm{~min}$ of maturation culture when most of the oocytes underwent GVBD. Together, the results suggest that the ADCY activities differ significantly between prepubertal and adult mouse oocytes. 
Table 1 Dosages of different drugs for efficient meiotic arrest of cumulus-oocyte complexes (COCs) or denuded oocytes (DOs) from prepubertal and adult mice which had been primed with different doses of equine chorionic gonadotropin (eCG) ${ }^{\mathrm{a}}$.

\begin{tabular}{|c|c|c|c|c|c|c|c|}
\hline \multirow[b]{2}{*}{ Drugs } & \multirow[b]{2}{*}{ Mice } & \multicolumn{2}{|c|}{0 -IU eCG } & \multicolumn{2}{|c|}{$3-I U$ eCG } & \multicolumn{2}{|c|}{ 10-IU eCG } \\
\hline & & $\mathrm{COC}$ & DO & $\mathrm{COC}$ & DO & $\mathrm{COC}$ & DO \\
\hline \multirow[t]{2}{*}{ Forskolin $(\mu \mathrm{M})$} & Prepub & 100 & $>500$ & 100 & $>500$ & 50 & $>500$ \\
\hline & Adult & 25 & 200 & 25 & 200 & 12.5 & 100 \\
\hline \multirow[t]{2}{*}{$\mathrm{HX}(\mathrm{mM})$} & Prepub & 5 & 4 & 5 & 4 & 5 & 4 \\
\hline & Adult & 4 & 3 & 4 & 3 & 4 & 3 \\
\hline \multirow[t]{2}{*}{ db-cAMP $(\mu \mathrm{M})$} & Prepub & 150 & 100 & 150 & 100 & 150 & 100 \\
\hline & Adult & 150 & 100 & 150 & 100 & 150 & 100 \\
\hline \multirow[t]{2}{*}{$\mathrm{H}-89(\mu \mathrm{M})^{\mathrm{b}}$} & Prepub & 25 & 25 & 25 & 25 & 25 & 25 \\
\hline & Adult & 25 & 25 & 25 & 25 & 25 & 25 \\
\hline \multirow[t]{2}{*}{$\mathrm{CHX}(\mu \mathrm{g} / \mathrm{ml})^{\mathrm{c}}$} & Prepub & $>100$ & $>100$ & 1 & $>100$ & 1 & $>100$ \\
\hline & Adult & $>100$ & $>100$ & 1 & $>100$ & 1 & $>100$ \\
\hline \multirow[t]{2}{*}{$\operatorname{ROS}(\mu \mathrm{M})$} & Prepub & 100 & 50 & 100 & 50 & 25 & 12.5 \\
\hline & Adult & 50 & 25 & 50 & 25 & 25 & 12.5 \\
\hline
\end{tabular}

${ }^{a}$ This table is a summary of results from six different experiments (tables) involving different drugs. In each experiment, four to eight drug concentrations (treatments) were tested to get an efficient dosage for meiotic arrest of prepubertal or adult COCs or DOs. The meiotic arrest was considered efficient when $90 \%$ of the oocytes treated were maintained at the GV stage. Each treatment was repeated three to four times with each replicate containing 20-25 oocytes. Oocytes were examined for GVBD at $4 \mathrm{~h}$ of culture in all experiments except for the experiment with $\mathrm{H}-89$ where GVBD was assessed at $24 \mathrm{~h}$ of culture. ${ }^{\mathrm{b}}$ Oocytes were cultured in the presence of both $\mathrm{H}-89$ and $150 \mu \mathrm{M} \mathrm{db}$-cAMP. ${ }^{\mathrm{C}}$ Oocytes were cultured in the presence of both $\mathrm{CXH}$ and $10 \mathrm{IU} / \mathrm{ml}$ eCG.

\section{Activities of the phosphodiesterase}

Oocytes were cultured for $4 \mathrm{~h}$ in the cultural medium supplemented with different concentrations of phosphodiesterase (PDE) inhibitor hypoxanthine (HX) before GVBD was examined. While $4 \mathrm{mM} \mathrm{HX}$ was enough to prevent GVBD of adult COCs, $5 \mathrm{mM} \mathrm{HX}$ was needed for GVBD inhibition in prepubertal COCs (Table 1). When the culture period was extended to $24 \mathrm{~h}$, however, the HX concentration for $90 \%$ GVBD inhibition became the same in prepubertal and adult oocytes $(5 \mathrm{mM}$, data not shown). Priming mice with eCG had no effect on the HX concentration needed for efficient GVBD inhibition. Given that the adult oocytes produced much more cAMP through their higher ADCY activities, the result that the same amount of $\mathrm{HX}$ was required for GVBD inhibition of both adult and prepubertal oocytes suggested that puberty and gonadotropin stimulation increased oocyte PDE activities.

\section{Activities of PRKA}

Oocytes were cultured in maturation medium supplemented with different concentrations of PRKA activator db-cAMP and/or inactivator $\mathrm{H}-89$ before GVBD was examined. When cultured for $4 \mathrm{~h}$ with db-cAMP alone, the db-cAMP concentration for efficient GVBD inhibition differed neither between prepubertal and adult nor between eCG-stimulated and eCG-unstimulated mice (Table 1). However, less db-cAMP was needed for efficient GVBD inhibition of DOs $(100 \mu \mathrm{M})$ than for COCs $(150 \mu \mathrm{M})$. When cultured for 4 or $8 \mathrm{~h}$ with both $\mathrm{H}-89(25 \mu \mathrm{M})$ and db-cAMP $(150 \mu \mathrm{M}), \mathrm{H}-89$ could not overcome the GV arrest by db-cAMP (data not shown). When cultured for $24 \mathrm{~h}$, however, H-89 overcame the
GVBD inhibition by db-cAMP, but its efficient concentration $(25 \mu \mathrm{M})$ differed neither between prepubertal and adult nor between eCG-stimulated and eCGunstimulated mice (Table 1). The results suggest that activities of PRKA do not differ between prepubertal and adult mouse oocytes.

\section{Synthesis of protein (cyclin B)}

Oocytes were cultured for $4 \mathrm{~h}$ in medium supplemented with different concentrations of cycloheximide (CHX) and $10 \mathrm{IU} / \mathrm{ml}$ eCG before GVBD examination. When mice were not primed with eCG, CHX $(100 \mu \mathrm{g} / \mathrm{ml})$ could not effectively inhibit GVBD of prepubertal or adult COCs (Table 1). After mice were primed with eCG, however, a low dose $(1 \mu \mathrm{g} / \mathrm{ml})$ of $\mathrm{CHX}$ efficiently inhibited GVBD of both prepubertal and adult COCs. $\mathrm{CHX}$ failed to prevent GVBD of DOs. The results suggested that CHX could not inhibit oocyte GVBD unless in the presence of eCG-primed cumulus cells.

\section{Activities of $C D C 2 A$}

Oocytes were cultured for $4 \mathrm{~h}$ in medium supplemented with different concentrations of $\mathrm{CDC} 2 \mathrm{~A}$ inhibitor roscovitine (ROS) before GVBD was examined. In unstimulated and 3-IU eCG-primed mice, while $50 \mu \mathrm{M}$ ROS prevented GVBD of adult COCs, GVBD in prepubertal COCs was not inhibited until the ROS dose increased to $100 \mu \mathrm{M}$ (Table 1). In mice stimulated with 10-IU eCG, however, the efficient concentration for GVBD inhibition decreased to $25 \mu \mathrm{M}$ in both adult and prepubertal COCs. The result suggested that CDC2A activities decreased significantly after puberty or eCG stimulation. 

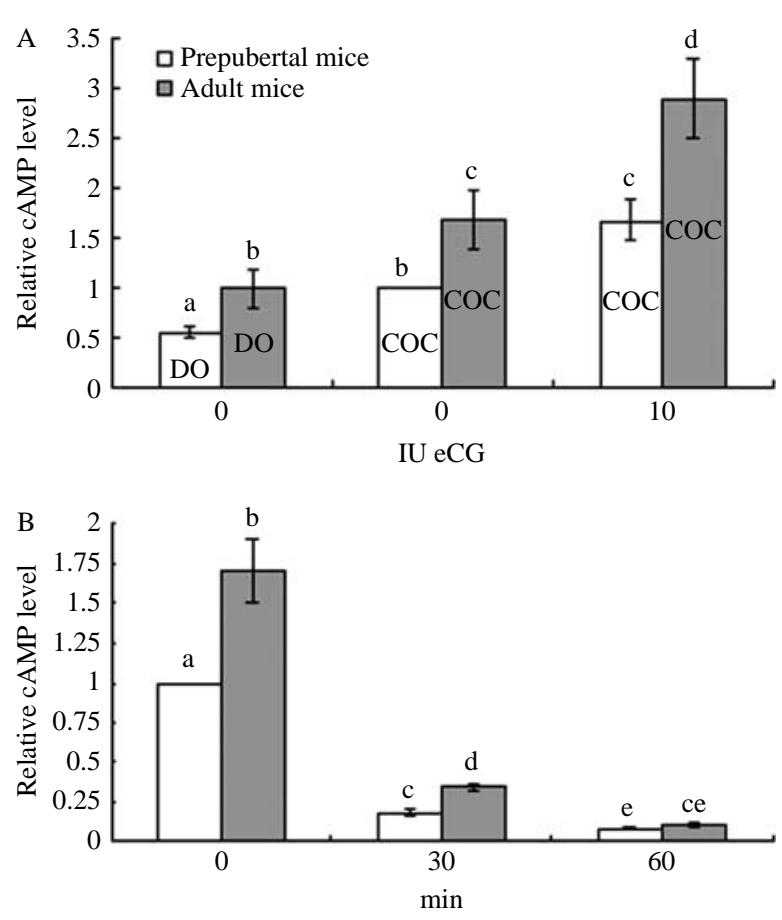

Figure 3 Relative levels of cAMP measured by capillary electrophoresis in different oocytes. (A) The relative level of CAMP in COCs and DOs at the GV stage immediately (within $10 \mathrm{~min}$ ) after collection from prepubertal or adult mice that had been stimulated with or without 10 IU of eCG. (B) The relative levels of cAMP in COCs from unstimulated mice when measured at 0 (immediately after collection), 30 , or 60 min of culture in maturation medium. The cAMP level of COCs from unstimulated prepubertal mice was arbitrarily set as 1 , and the other values were expressed relative to this level. Means without a common letter above their bars differ $(P<0.05)$.

\section{Effects of puberty and eCG stimulation on the distribution of CDC2A protein in mouse oocytes prior to meiotic resumption}

Since the above results suggested that the activities of CDC2A differed significantly between prepubertal and adult oocytes, and CDC2A is known to be the molecule that directly determines the MPF activity, we observed its distribution in different mouse oocytes prior to meiotic resumption. Oocytes collected from prepubertal or adult mice that had been primed with or without eCG were immediately labeled with anti-CDC2A antibodies and observed under a laser confocal microscope. Oocytes were classified into those with (Fig. 4A-C) and those without (Fig. 4D-F) nuclear concentration of the CDC2A protein. In unstimulated mice, while the majority (over $70 \%$ ) of the adult oocytes showed nuclear concentration of CDC2A protein, most (over $80 \%$ ) of the prepubertal oocytes showed no CDC2A protein in the GV region (Table 2 ). A negligible number $(<2 \%$ ) of the meiotically incompetent oocytes obtained from mice on day 10 after birth showed CDC2A concentration in the nucleus. Priming mice with eCG facilitated CDC2A translocation to the GV in both prepubertal and adult oocytes.
The in vivo maturing oocytes collected $2.5 \mathrm{~h}$ post hCG from superovulated mice showed a percentage of $\mathrm{CDC} 2 \mathrm{~A}$ nuclear concentration similar to that in fullygrown oocytes from eCG-primed mice, indicating that the delayed GVBD during in vivo compared to in vitro maturation was not due to a delayed translocation of CDC2A into the nucleus but might be controlled by other mechanisms. To further substantiate our conclusion that the slow meiotic progression of prepubertal oocytes was due to their delayed localization of CDC2A in the GV, GV karyoplasts prepared from unstimulated prepubertal or adult mouse oocytes were electrically fused with in vitro matured adult mouse oocytes, and the fusion-GVBD interval was compared. The results showed that the interval was significantly longer in prepubertal oocytes $(21.4 \pm 0.8 \mathrm{~min}, n=26)$ than in adult oocytes $(17.7 \pm 0.9, n=30)$, indicating that the GV of prepubertal mouse oocytes indeed contained less CDC2A protein than that of the adult mouse oocytes.

\section{Discussion}

In this study, while meiotic progression was significantly slower in prepubertal than in adult mouse oocytes, assay for histone $\mathrm{H} 1$ kinase activity and tests for GVBD-inducing efficiency and susceptibility to activating stimuli all unequivocally showed that the MPF activity of prepubertal oocytes was significantly higher than that of adult oocytes. Furthermore, analyses for the activities of ADCY and CDC2A also suggested that prepubertal oocytes had higher MPF activities than the adult oocytes. The nuclear maturation of calf oocytes also went slower than that of cow oocytes (Khatir et al. 1998b). However, the MPF activities in calf and lamb oocytes were significantly lower than in cow and ewe oocytes (Ledda et al. 2001, Salamone et al. 2001). The meiotically incompetent mouse oocytes obtained 10-12 days after birth showed low concentrations of CDC2A, but the amount of CDC2A increased with the acquisition of meiotic competence 20 days after birth (Mitra \& Schultz 1996, de Vant'ery et al. 1996). The prepubertal mouse oocytes used in this study were recovered 21 days after birth, and the calf and lamb oocytes used in their studies were all of meiotic competence (Ledda et al. 2001, Salamone et al. 2001). Therefore, the difference in MPF activities between prepubertal mouse and calf/lamb oocytes might suggest a species difference in the mechanisms by which oocytes acquire meiotic competence. It also questions whether the MPF activity can be used as a marker for ooplasmic maturation or developmental potential of oocytes and whether it is representative to use prepubertal mouse oocytes for some studies.

Although difference in MPF activities has been observed between prepubertal and adult animal oocytes, the specific steps that puberty or gonadotropin regulate in the signaling pathways leading to oocyte meiotic 

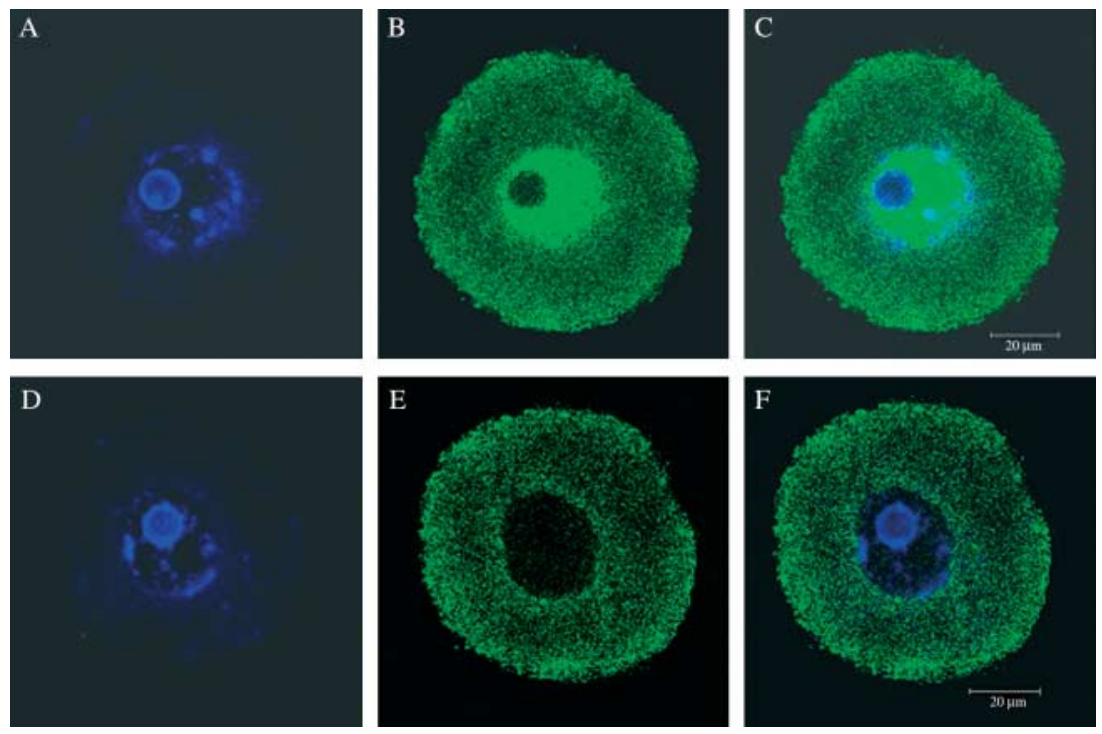

Figure 4 Laser-scanning confocal microscope images of adult and prepubertal mouse oocytes stained for CDC2A. (A-C) An adult mouse oocyte with CDC2A concentrated in the GV. (D-F) A prepubertal mouse oocyte that shows no nuclear concentration of the protein. Images $A$ and D show the Hoechst-stained chromatin (blue), B and E show the FITC-labeled CDC2A protein (green), and $C$ and $F$ are the merged pictures of $A$ and $B$ and of $D$ and $E$ respectively. The scale bar is $20 \mu \mathrm{m}$. resumption have yet to be specified. In this study, the effects of puberty and gonadotropins on the major signaling events controlling oocyte meiotic resumption were tentatively determined by testing the activities of the related enzymes using corresponding enzyme regulators. The results suggested that while the activity of PRKA was unaffected, the activity of ADCY and PDE increased while that of CDC2A decreased significantly after puberty or eCG stimulation. While meiotic resumption was prevented when oocytes from domestic animals including pigs were cultured in the presence of protein synthesis inhibitors, oocytes from mice underwent GVBD in the presence of such inhibitors (Fulka et al. 1986). The present study demonstrated that although GVBD occurred when mouse GV oocytes were cultured in the presence of $\mathrm{CHX}$ alone (data not shown), it was prevented in the presence of both $\mathrm{CHX}$ and eCG. A study has been conducted recently in this

Table 2 Percentages of oocytes with nuclear concentration of cell division cycle 2 homolog A (CDC2A) when oocytes of different mouse age groups were stained with anti-CDC2A antibodies and observed under a laser confocal microscope.

\begin{tabular}{lccc}
\hline Mice & $\begin{array}{c}\text { eCG } \\
\text { (IU/mouse) }\end{array}$ & $\begin{array}{c}\text { Oocytes } \\
\text { observed }\end{array}$ & $\begin{array}{c}\text { Percentage of } \\
\text { oocytes with nuclear } \\
\text { concentration }\end{array}$ \\
\hline Day 10 post birth & 0 & 123 & $1.8 \pm 1.0^{\mathrm{a}}$ \\
Prepubertal & 0 & 68 & $16.9 \pm 2.5^{\mathrm{b}}$ \\
& 3 & 64 & $23.1 \pm 3.0^{\mathrm{b}}$ \\
Adult & 10 & 42 & $82.3 \pm 6.5^{\mathrm{c}}$ \\
& $10^{*}$ & 61 & $86.6 \pm 1.0^{\mathrm{c}}$ \\
& 0 & 46 & $71.6 \pm 1.3^{\mathrm{d}}$ \\
& 10 & 48 & $81.5 \pm 2.7^{\mathrm{c}}$ \\
& $10^{*}$ & 52 & $86.8 \pm 1.2^{\mathrm{c}}$
\end{tabular}

\footnotetext{
${ }^{a-d}$ Values without a common letter in their superscripts in the same column differ $(P<0.05)$.

*In vivo maturing oocytes collected from superovulated mice $2.5 \mathrm{~h}$ post hCG injection.
}

laboratory to explore the mechanism by which eCG enables GVBD inhibition by $\mathrm{CHX}$, and it showed that 1) cyclin B decreased when mouse GV oocytes were cultured in the presence of $\mathrm{CHX}$ and 2) eCG stimulated cumulus cells to produce CAMP, which maintained meiotic arrest for a period enough for the already existing cyclin B to break down and thus enabled $\mathrm{CHX}$ to inhibit GVBD by preventing synthesis of new cyclin B (D Han, XY Liu, B Liang, N He, WQ Gao \& JH Tan, unpublished data). Therefore, although direct measurement of cyclin B synthesis was not conducted in the present study, the results suggest that $\mathrm{CHX}$ maintains meiotic arrest of mouse oocytes by inhibiting cyclin B synthesis.

In agreement with the present results, treatment of immature rats with eCG increased both CAMP levels and PDE activities in ovarian homogenates (Wang et al. 2007), and gonadotropin stimulation caused the activation of PDE via an increase in CAMP in cultured Sertoli (Conti et al. 1982) and granulosa cells (Conti et al. 1984). Further studies demonstrated that TSH quickly activated the cAMP-specific PDE in the thyroid cells through a phosphorylation mediated by the catalytic subunit of PRKA (Sette et al. 1994). A loop of gonadotropin $\rightarrow$ increased $\mathrm{CAMP} \rightarrow$ activated $\mathrm{PRKA} \rightarrow$ activated $\mathrm{PDE} \rightarrow$ decreased CAMP has been involved in the refractoriness of the Sertoli cells to a second FSH stimulation (Conti et al. 1983). The same loop would also help to explain the elevated PDE activities in the adult compared to prepubertal mouse oocytes and to explain why the same amount of db-cAMP was needed for the inhibition of GVBD in both adult and prepubertal oocytes even though the former contained much more cAMP than the latter. Unlike cAMP, its lipophilic analog db-cAMP is not hydrolyzed by PDE (Kaukel \& Hilz 1972). In smooth muscle cells, treatment with db-cAMP significantly increased PDE activities (Rose et al. 1997, Tilley \& Maurice 2002). 
Using doses of db-cAMP which override the difference in the natural cAMP level between prepubertal and adult oocytes, we demonstrated that these two groups of oocytes had a similar PRKA activity. However, the CDC2A activity was lower in adult than in prepubertal mouse oocytes. Activities of PDE3 in rat oocytes increased significantly in vitro prior to meiotic resumption, but returned to the basal level at the peak of GVBD (Richard et al. 2001). In this study, while cAMP levels declined significantly prior to GVBD in both prepubertal and adult oocytes, the cAMP level of adult was still higher than that of prepubertal oocytes. This suggested that although both ADCY and PDE activities were higher in adult than prepubertal oocytes, the elevated PDE activities could not hydrolyze as much as cAMP produced by elevated ADCY activities in adult oocytes. The remaining higher level of CAMP, by activating PRKA as well as inhibiting cyclin B synthesis (Josefsberg et al. 2003), would inactivate more CDC2A in adult than prepubertal oocytes. Although an active PRKA prevents meiotic resumption in both fully-grown and growing rat oocytes, PRKA in the growing oocytes is activated at relatively low cAMP concentrations, while its activation in fully-grown oocytes is maintained at high levels of cAMP (Goren et al. 1994, Kovo et al. 2006). Thus, while a fall in intra-oocyte cAMP levels inactivates PRKA of fully-grown oocytes leading to meiotic resumption, a similar reduction in intra-oocyte cAMP concentrations in growing, meiotically incompetent oocytes does not result in resumption of meiosis. Therefore, the present results that CAMP levels declined sharply prior to GVBD in both prepubertal and adult oocytes suggest that the PRKA of these two groups of oocytes has a similar sensitivity to CAMP.

To investigate the contradiction between the slow meiotic progression and the high MPF activity observed in prepubertal mouse oocytes, we examined the distribution of the CDC2A kinase in mouse oocytes at the GV stage. While most of the adult oocytes showed CDC2A protein concentrated in the GV region, most of the prepubertal oocytes showed no nuclear concentration of CDC2A protein. When GV karyoplasts from unstimulated prepubertal or adult mouse oocytes were electrically fused with in vitro matured adult mouse oocytes, the fusion-GVBD interval was significantly longer in prepubertal oocytes than in adult oocytes, indicating that the GV of prepubertal mouse oocytes indeed contained less CDC2A protein than that of the adult mouse oocytes. Mitra \& Schultz (1996) reported an increase in the nuclear concentration of both CDC2A and cyclin B proteins in adult mouse oocytes compared to the meiotically incompetent oocytes obtained from 10-day-old prepubertal mice. We also observed no nuclear concentration of CDC2A protein in meiotically incompetent mouse oocytes. This suggests that the translocation of MPF activities toward the nucleus is a continuous process that occurs not only during but also after oocytes' acquisition of meiotic competence. It also suggests that the resumption of meiosis in mouse oocytes requires not only activation but also concentration of the activated MPF in the GV region. Whether the slow meiotic progression in calf oocytes (Khatir et al. 1998b) was due to a failure to activate enough MPF or delayed $\mathrm{CDC} 2 \mathrm{~A}$ translocation needs investigation. In somatic cells, the active cyclin B1-CDC2A complex must translocate to the nucleus to begin phosphorylating nuclear substrates at the $\mathrm{G}_{2} / \mathrm{M}$ transition (Takizawa \& Morgan 2000, Porter \& Donoghue 2003). Moreover, in starfish oocytes, CDC2A-cyclin B complex is indeed activated in the cytoplasm prior to its translocation to the nucleus (Ookata et al. 1992). However, it is also possible that activation of MPF is slower in prepubertal mouse oocytes before GVBD but reaches higher levels at the MI or MII stage when compared with those in adult mouse oocytes. To test this possibility, GV oocytes from unstimulated prepubertal and adult mice were cultured in maturation medium for $45 \mathrm{~min}$ or $1 \mathrm{~h}$ before assayed for MPF activities. The results indicated that MPF activities differed between prepubertal and adult oocytes neither at $45 \mathrm{~min}(49.5 \pm 2.7$ vs $46.5 \pm 1.3 \%)$, when all of the oocytes were at the GV stage, nor at $1 \mathrm{~h}$ of culture $(51.0 \pm 2.0$ vs $52.1 \pm 1.9 \%)$, when $70 \%$ of the prepubertal oocytes were at the GV stage while $70 \%$ of the adult oocytes were already in the pMI stage. Together with the result that MPF activity became higher immediately after GVBD in prepubertal than in adult mice, this ruled out the possibility that a delayed MPF activation before GVBD had led to the slow meiotic progression in prepubertal mouse oocytes compared to that in adult mouse oocytes.

In this study, maximally priming mice with eCG quickened the meiotic progression of the prepubertal oocytes by promoting translocation of the MPF activities to the nucleus, while they reduced their MPF activities by increasing the ADCY activity to approach the level in adult oocytes. The hormonal basis of puberty is thought to be very similar to that of metamorphosis (Gilbert 1985). Thus, while the metamorphosis of both amphibians and insects is regulated by hormonal changes that are initiated by $\mathrm{TSH}-\mathrm{RH}$ and prothoracicotropic hormone from the brain, the changes associated with human puberty are initiated by GNRH from the hypothalamus of the brain. According to Grumbach et al. (1974), before puberty, the child secretes a small amount of GNRH, so that the circulating LH and FSH are very small. Therefore, the gonad remains immature and secretes little estrogen or testosterone. Furthermore, the hypothalamus is highly sensitive to these sex hormones at this time and turns off GNRH production when circulating sex hormones get above their very low levels. At the onset of puberty, the hypothalamus becomes less responsive to the negative feedback of sex hormones, and thus secretes more GNRH, ultimately inducing further differentiation of gonads and the release of 
more sex hormones. The present results suggest that like those changes in bodily form and physiology, the puberty-associated changes in the molecular events controlling meiotic progression are also controlled by gonadotropins.

In view of the important role of cumulus cells in oocyte maturation (Tanghe et al. 2002), we observed the effect of cumulus cells on the signaling events regulating meiotic resumption of prepubertal and adult mouse oocytes. The results suggested that the ADCY activities in cumulus cells participated in the maintenance of oocyte meiotic arrest by producing CAMP, and this was stimulated by both puberty and gonadotropins. The cAMP could be produced either by the oocyte or by cumulus cells. One long-standing hypothesis is that cAMP is produced by follicle cells, and diffuses through gap junctions to the oocyte (Bornslaeger \& Schultz 1985, Dekel 1988, Webb et al. 2002). However, several lines of evidence support the hypothesis that the oocyte produces its own cAMP through a G-protein-linked receptor in the oocyte plasma membrane that stimulates $\mathrm{G}_{\mathrm{s}}$ and, subsequently, ADCY (Olsiewski \& Beers 1983, Urner et al. 1983, Downs et al. 1992, Mehlmann 2005).

In summary, we have studied the effects of puberty as well as gonadotropins on meiotic progression and some of the molecular events controlling meiotic resumption of oocytes. While oocyte meiotic progression was significantly slower in prepubertal than in adult mice, the MPF activity of prepubertal oocytes was significantly higher than that of adult oocytes. Our experiments using corresponding regulators suggested that while oocyte activities of PRKA were unaffected, the activities of ADCY and PDE increased while that of CDC2A decreased significantly after puberty. While most of the adult oocytes had CDC2A protein concentrated in the GV region, the majority of prepubertal oocytes showed no nuclear concentration of CDC2A. Maximally priming a mouse with eCG brought these parameters of prepubertal oocytes close to those in adult oocytes. Taken together, this study suggests that puberty controls oocyte meiotic progression mainly via gonadotropins, which stimulate the ADCY activities and the concentration of the activated MPF toward the GV region. Puberty-associated molecular changes are important subjects in developmental biology and endocrinology, and knowledge of the efficient mechanisms and the downstream cascades of the key molecules controlling oocyte maturation may lead to improvement of the present oocyte culture systems and gamete biotechnology.

\section{Materials and Methods}

All chemicals and reagents used in this study were purchased from Sigma Chemical Company unless otherwise specified.

\section{Oocyte recovery}

Mice of the Kunming breed were kept in a room with $14 \mathrm{~h}$ light: $10 \mathrm{~h}$ darkness cycles, with the dark cycle starting at $2000 \mathrm{~h}$. The prepubertal mice were used for experiments 21-22 days after birth, while adult mice were used 6-8 weeks after birth. The animals were handled by the rules stipulated by the Animal Care and Use Committee of Shandong Agricultural University.

\section{Fully-grown oocytes at the GV stage}

Prepubertal or adult female mice were killed at $46 \mathrm{~h}$ after injection of eCG $(0,3$, or $10 \mathrm{IU} /$ mouse), and the large follicles on the ovary were punctured in M2 medium to release COCs. Only COCs with more than three layers of unexpanded cumulus cells and containing oocytes $>75 \mu \mathrm{m}$ in diameter with a homogenous cytoplasm were selected. To prepare cumulus-DOs, some COCs were freed of cumulus cells by pipetting with a thin pipette.

\section{In vivo maturing oocytes}

Prepubertal and adult female mice were induced to superovulate with different doses of eCG followed $48 \mathrm{~h}$ later by hCG (10 IU/mouse). Both eCG and hCG were obtained from Ningbo Hormone Product Co. Ltd, Cixi City, People's Republic of China. The superovulated mice were killed, and ovarian follicles were broken to release COCs at different times after hCG injection.

\section{In vitro culture of oocytes}

The COCs and DOs at the GV stage were cultured for different times in drops of $100 \mu \mathrm{l}$ medium (20-25 oocytes/drop), covered with mineral oil, at $37{ }^{\circ} \mathrm{C}$ under $5 \% \mathrm{CO}_{2}$ in humidified air. Oocytes for inhibition treatment were cultured in maturation medium supplemented with different drugs, while the oocytes for maturation were cultured in the maturation medium alone. The maturation medium was TCM-199 (Gibco) supplemented with $24.2 \mathrm{mg} / \mathrm{l}$ sodium pyruvate and $3 \mathrm{mg} / \mathrm{ml}$ BSA. Forskolin, ROS, db-cAMP, CHX, and $\mathrm{H}-89$ were prepared as stock solutions and stored in aliquots at $-20^{\circ} \mathrm{C}$ until use. $\mathrm{HX}$ was dissolved in maturation medium immediately before use.

\section{Assessment of meiotic progression}

Cumulus-free oocytes were mounted on glass slides and fixed in ethanol:acetic acid $(3: 1, \mathrm{v} / \mathrm{v})$ for at least $24 \mathrm{~h}$. Oocytes were stained in $1 \%$ aceto-orcein and examined under a phasecontrast microscope. Meiotic progression was classified into the $\mathrm{GV}, \mathrm{pMI}, \mathrm{Ml}, \mathrm{A} / \mathrm{Tl}$, and MIl stages.

\section{Histone H1 kinase assay}

Thirty cumulus-free oocytes from each treatment were washed with histone kinase buffer, transferred to $10 \mu$ l histone kinase buffer in a $1.5 \mathrm{ml}$ microfuge tube, and frozen-stored at $-80^{\circ} \mathrm{C}$ (Wu et al. 1997). The frozen samples were subjected to four to five times freezing and thawing to prepare lysates. Then, $10 \mu \mathrm{l}$ 
of substrate buffer containing $2 \mathrm{mg} / \mathrm{ml}$ histone $\mathrm{H} 1,2 \mathrm{mM}$ dithiothreitol, and $20 \mu \mathrm{Ci} / \mathrm{ml}\left[\gamma_{-}{ }^{32} \mathrm{P}\right]$ ATP were added to each sample, and the reactions were carried out for $50 \mathrm{~min}$ at $36{ }^{\circ} \mathrm{C}$. Finally, an equal volume of double-strength SDS sample buffer containing $\beta$-mercaptoethanol was added, and the mixture was boiled for 3-5 min. Kinase reaction products were separated by $12 \%$ linear gradient SDS-PAGE. Gels were exposed to phosphor screens. Data acquisition was the actual scanning of sample images with the Cyclone Plus Storage Phosphor System to create an image file that can be analyzed by the OptiQuant Image Analysis Software. The histone $\mathrm{H} 1$ kinase activity values of in vivo matured oocytes collected $11 \mathrm{~h}$ after hCG injection from mice superovulated with eCG (3 IU/mouse) were arbitrarily set as $100 \%$, and the other values were expressed relative to this activity.

\section{Fusion between GV karyoplast and MII oocyte}

Micromanipulation was conducted under a Leica inverted microscope equipped with differential interference contrast and a piezo-driven injection pipette. Cumulus-denuded GV oocytes were manipulated in a droplet of HCZB medium containing $5 \mu \mathrm{g} / \mathrm{ml}$ cytochalasin B and $0.2 \mathrm{mM} \mathrm{IBMX}$ to obtain karyoplasts containing intact GV. Then, the MII oocytes were transferred to the same droplet, and a karyoplast was inserted into the perivitelline space of each MII oocyte. The karyoplast-oocyte complexes were then fused electrically using an electrofusion instrument with two microelectrodes (BEXLF201; Nepa Gene Co. Ltd, Shioyaki Ichikawa Chiba, Japan). Fusion and GVBD were observed under a microscope soon after pulsing.

\section{Oocyte activation}

Cumulus-free oocytes were incubated in $\mathrm{Ca}^{2+}$-free $\mathrm{CZB}$ supplemented with $10 \mathrm{mM} \mathrm{SrCl}{ }_{2}$ for $2 \mathrm{~h}$, followed by a $4-\mathrm{h}$ culture in $\mathrm{Ca}^{2+}$-free $\mathrm{CZB}$ without $\mathrm{SrCl}_{2}$ at $37^{\circ} \mathrm{C}$ in $5 \% \mathrm{CO}_{2}$ in humidified air. At the end of treatment, oocytes were examined for activation. Only the oocytes showing well-developed pronuclei were considered activated.

\section{Capillary electrophoresis for cAMP measurement}

Capillary electrophoresis was performed on a P/ACE-MDQ system (Beckman Coulter, Fullerton, CA, USA). The samples were analyzed in an electrolyte consisting of $20 \mathrm{mM}$ glycylglycine solutions with $20 \mathrm{mM}$ boron ( $\mathrm{pH}$ 8.4). Sample separation was run for $20 \mathrm{~min}$ at $20^{\circ} \mathrm{C}$ with an applied voltage of $20 \mathrm{kV}$ positively. Analytes were detected by an excitation wavelength of $214 \mathrm{~nm}$. Before sample runs or between two samples run, the capillary was thoroughly rinsed. Pure CAMP was first detected to determine the migration time. Oocytes were washed with electrolyte, transferred to a $1.5 \mathrm{ml}$ microfuge tube at a density of 4 oocytes/ $\mu$ l electrolyte, and frozen-stored at $-80{ }^{\circ} \mathrm{C}$. The frozen samples were subjected to four times freezing and thawing to prepare lysates. The CAMP level of COCs from unstimulated prepubertal mice was arbitrarily set as 1, and the other values were expressed relative to this level.

\section{CDC2A staining and laser-scanning confocal microscopy}

Zona-free oocytes were 1) fixed with $3.7 \%$ paraformaldehyde overnight at $4{ }^{\circ} \mathrm{C} ; 2$ ) incubated in $0.1 \%$ BSA and $0.01 \%$ Tween20 in PBS (blocking solution) for $15 \mathrm{~min} ; 3$ ) incubated for $1.5 \mathrm{~h}$ in the blocking solution containing the anti-CDC2A antibodies (a mouse MAB from Santa Cruz Biotechnology) at a dilution of $1: 50 ; 4)$ incubated for $60 \mathrm{~min}$ in the dark in blocking solution containing the sheep anti-mouse IgG-FITC antibodies at a dilution of $1: 100$; 5) stained with Hoechst 33 342; 6) mounted and observed with a Leica confocal microscope. In each experiment, negative control samples in which the primary antibody was omitted were also evaluated.

\section{Data analysis}

There were at least three replicates for each treatment. Percentage data were arc-sine transformed and analyzed with ANOVA; a Duncan multiple comparison test was used to locate differences. The software used was Statistics Package for Social Science (SPSS 11.5, Chicago, IL, USA). Data were expressed as mean \pm s.E.M., and $P<0.05$ was considered significant.

\section{Declaration of interest}

The authors declare that there is no conflict of interest that could be perceived as prejudicing the impartiality of the research reported.

\section{Funding}

This study was supported by grants from the National Basic Research Project of the China Ministry of Science and Technology (Nos 2006CB944003 and 2007CB947403), the China National Natural Science Foundation (Nos 30771556 and 30972096), and the National '863' Project of the China Ministry of Science and Technology (Nos 2008AA10Z160 and 2008AA101003).

\section{References}

Armstrong DT, Zhang X, Vanderhyden BC \& Khamsi F 1991 Hormonal actions during oocyte maturation influence fertilization and early embryonic development. Annals of the New York Academy of Sciences 626 137-158.

Bornslaeger EA \& Schultz RM 1985 Regulation of mouse oocyte maturation: effect of elevating cumulus cell cAMP on oocyte cAMP levels. Biology of Reproduction 33 698-704.

Conti M, Toscano MV, Petrelli L, Geremia R \& Stefanini M 1982 Regulation of follicle-stimulating hormone and dibutyryl adenosine $3^{\prime}, 5^{\prime}$ monophosphate of a phosphodiesterase isoenzyme of the Sertoli cell. Endocrinology 110 1189-1196.

Conti M, Toscano MV, Petrelli L, Geremia R \& Stefanini M 1983 Involvement of phosphodiesterase in the refractoriness of the Sertoli cell. Endocrinology 113 1845-1853.

Conti M, Kasson BG \& Hsueh AJ 1984 Hormonal regulation of 3',5' adenosine monophosphate phosphodiesterases in cultured rat granulosa cells. Endocrinology 114 2361-2368. 
Damiani P, Fissore RA, Cibelli JB, Long CR, Balise JJ, Robl JM \& Duby RT 1996 Evaluation of developmental competence, nuclear and ooplasmic maturation of calf oocytes. Molecular Reproduction and Development 45 521-534.

Dekel N 1988 Regulation of oocyte maturation. The role of cAMP. Annals of the New York Academy of Sciences 541 211-216.

Downs SM, Buccione R \& Eppig JJ 1992 Modulation of meiotic arrest in mouse oocytes by guanyl nucleotides and modifiers of G-proteins. Journal of Experimental Zoology 262 391-404.

Eppig JJ, Schroeder AC \& O'Brien MJ 1992 Developmental capacity of mouse oocytes matured in vitro: effects of gonadotrophic stimulation, follicular origin and oocyte size. Journal of Reproduction and Fertility 95 119-127.

Fulka J Jr, Motlík J, Fulka J \& Jílek F 1986 Effect of cycloheximide on nuclear maturation of pig and mouse oocytes. Journal of Reproduction and Fertility 77 281-285.

Gandolfi F, Milanesi E, Pocar P, Luciano AM, Brevini TAL, Acocella F, Lauria A \& Armstrong DT 1998 Comparative analysis of calf and cow oocytes during in vitro maturation. Molecular Reproduction and Development 49 168-175.

Gilbert SF 1985 Cell interactions at a distance: hormones as mediators of development. In Developmental Biology, pp 603-637. Ed. SF Gilbert. Sunderland, MA, USA: Sinauer Associates, Inc., Publishers.

Gilman AG 1990 Regulation of adenylyl cyclase by G proteins. Advances in Second Messenger and Phosphoprotein Research 24 51-57.

Goren S, Piontkewitz Y \& Dekel N 1994 Meiotic arrest in incompetent rat oocytes is not regulated by cAMP. Developmental Biology 166 11-17.

Gosden R, Krapez J \& Briggs D 1997 Growth and development of the mammalian oocyte. BioEssays 19 875-882.

Grumbach MM, Roth JC, Kaplan SL \& Kelch RP 1974 Hypothalamicpituitary regulation of puberty in man: evidence and concepts derived from clinical research. In Control of the Onset of Puberty, pp 115-166. Eds MM Grumbach, GD Grave \& FE Meyer. New York, NY: Wiley.

Hamberger L, Nordenström K, Rosberg S \& Sjögren A 1978 Acute influence of $\mathrm{LH}$ and $\mathrm{FSH}$ on cyclic AMP formation in isolated granulosa cells of the rat. Acta Endocrinologica 88 567-579.

Han SJ \& Conti M 2006 New pathways from PKA to the Cdc2/cyclin B complex in oocytes: Wee1B as a potential PKA substrate. Cell Cycle 5 $227-231$.

Hunzicker-Dunn M \& Birnbaumer L 1976 Adenylyl cyclase activities in ovarian tissues. III. Regulation of responsiveness to LH, FSH, and PGE1 in the prepubertal, cycling, pregnant, and pseudopregnant rat. Endocrinology 99 198-210.

Hyttel P, Fair T, Callesen H \& Greve T 1997 Oocyte growth, capacitation and final maturation in cattle. Theriogenology 47 23-32.

Izquierdo D, Villamediana P \& Paramio MT 1999 Effect of culture media on embryo development from prepubertal goat IVM-IVF oocytes. Theriogenology 52 847-861.

Josefsberg LB, Galiani D, Lazar S, Kaufman O, Seger R \& Dekel N 2003 Maturation-promoting factor governs mitogen-activated protein kinase activation and interphase suppression during meiosis of rat oocytes. Biology of Reproduction 68 1282-1290.

Kaukel E \& Hilz H 1972 Permeation of dibutyryl cAMP into HeLa cells and its conversion to monobutyryl cAMP. Biochemical and Biophysical Research Communications 46 1011-1018.

Khatir H, Lonergan P, Carolan C \& Mermillod P 1996 Prepubertal bovine oocyte: a negative model for studying oocyte developmental competence. Molecular Reproduction and Development 45 231-239.

Khatir H, Lonergan P, Touzé JL \& Mermillod P 1998a The characterization of bovine embryos obtained from prepubertal calf oocytes and their viability after non-surgical embryo transfer. Theriogenology $\mathbf{5 0}$ 1201-1210.

Khatir H, Lonergan P \& Mermillod P 1998 binetics of nuclear maturation and protein profiles of oocytes from prepubertal and adult cattle during in vitro maturation. Theriogenology 50 917-929.

Koeman J, Keefer CL, Baldassarre H \& Downey BR 2003 Developmental competence of prepubertal and adult goat oocytes cultured in semidefined media following laparoscopic recovery. Theriogenology 60 879-889.

Kolena J \& Channing CP 1972 Stimulatory effects of LH, FSH and prostaglandins upon cyclic $3^{\prime}, 5^{\prime}$-AMP levels in porcine granulosa cells. Endocrinology 90 1543-1550.
Kovo M, Kandli-Cohen M, Ben-Haim M, Galiani D, Carr DW \& Dekel N 2006 An active protein kinase $A$ (PKA) is involved in meiotic arrest of rat growing oocytes. Reproduction 132 33-43.

Ledda S, Bogliolo L, Calvia P, Leoni G \& Naitana S 1997 Meiotic progression and developmental competence of oocytes collected from juvenile and adult ewes. Journal of Reproduction and Fertility 109 73-78.

Ledda S, Bogliolo L, Leoni G \& Naitana S 2001 Cell coupling and maturation-promoting factor activity in in vitro-matured prepubertal and adult sheep oocytes. Biology of Reproduction 65 247-252.

Lindsey AM \& Channing CP 1979 Comparison of the stimulatory effects of ovine, porcine and human follicle-stimulating hormone and of ovine and human luteinizing hormone on the accumulation of cyclic AMP by porcine granulosa cells. Journal of Endocrinology 80 9-20.

Mehlmann LM 2005 Stops and starts in mammalian oocytes: recent advances in understanding the regulation of meiotic arrest and oocyte maturation. Reproduction 130 791-799.

Mitra J \& Schultz RM 1996 Regulation of the acquisition of meiotic competence in the mouse: changes in the subcellular localization of cdc2, cyclin B1, cdc25C and wee1, and in the concentration of these proteins and their transcripts. Journal of Cell Science 109 $2407-2415$.

O'Brien JK, Dwarte D, Ryan JP, Maxwell WM \& Evans G 1996 Developmental capacity, energy metabolism and ultrastructure of mature oocytes from prepubertal and adult sheep. Reproduction, Fertility, and Development 8 1029-1037.

O'Brien JK, Catt SL, Ireland KA, Maxwell WMC \& Evans G 1997 In vitro and in vivo developmental capacity of oocytes from prepubertal and adult sheep. Theriogenology 47 1433-1443.

Olsiewski PJ \& Beers WH 1983 cAMP synthesis in the rat oocyte. Developmental Biology 100 287-293.

Ookata K, Hisanaga S, Okano T, Tachibana K \& Kishimoto T 1992 Relocation and distinct subcellular localization of p34cdc2-cyclin B complex at meiosis reinitiation in starfish oocytes. EMBO Journal $\mathbf{1 1}$ $1763-1772$.

Pinkert CA, Kooyman DL, Baumgartner A \& Keisler DH 1989 In vitro development of zygotes from superovulated prepubertal and mature gilts. Journal of Reproduction and Fertility 87 63-66.

Porter LA \& Donoghue DJ 2003 Cyclin B1 and CDK1: nuclear localization and upstream regulators. Progress in Cell Cycle Research 5 335-347.

Ptak G, Loi P, Dattena M, Tischner M \& Cappai P 1999 Offspring from onemonth-old lambs: studies on the developmental capability of prepubertal oocytes. Biology of Reproduction 61 1568-1574.

Revel F, Mermillod P, Peynot N, Renard JP \& Heyman Y 1995 Low developmental capacity of in vitro matured and fertilized oocytes from calves compared with that of cows. Journal of Reproduction and Fertility 103 115-120.

Richard FJ, Tsafriri A \& Conti M 2001 Role of phosphodiesterase type 3A in rat oocyte maturation. Biology of Reproduction 65 1444-1451.

Rose RJ, Liu H, Palmer D \& Maurice DH 1997 Cyclic AMP-mediated regulation of vascular smooth muscle cell cyclic AMP phosphodiesterase activity. British Journal of Pharmacology 122 233-240.

Salamone DF, Damiani P, Fissore RA, Robl JM \& Duby RT 2001 Biochemical and developmental evidence that ooplasmic maturation of prepubertal bovine oocytes is compromised. Biology of Reproduction 64 1761-1768.

Seidel GE, Larson LL Jr, Spilman CH, Hahn J \& Foote RH 1971 Culture and transfer of calf ova. Journal of Dairy Science 54 923-926.

Sette C, Iona S \& Conti M 1994 The short-term activation of a rolipramsensitive, cAMP-specific phosphodiesterase by thyroid-stimulating hormone in thyroid FRTL-5 cells is mediated by a cAMP-dependent phosphorylation. Journal of Biological Chemistry 269 9245-9252.

Sirard MA \& Blondin P 1996 Oocyte maturation and IVF in cattle. Animal Reproduction Science 42 417-426.

Sirard MA, Florman HM, Leibfried-Rutledge ML, Barnes FL, Sims ML \& First NL 1989 Timing of nuclear progression and protein synthesis necessary for meiotic maturation of bovine oocytes. Biology of Reproduction 40 1257-1263.

Sirard MA, Desrosier S \& Assidi M 2007 In vivo and in vitro effects of FSH on oocyte maturation and developmental competence. Theriogenology $68 \mathrm{~S} 71-\mathrm{S} 76$. 
Takizawa CG \& Morgan DO 2000 Control of mitosis by changes in the subcellular location of cyclin-B1-Cdk1 and Cdc25C. Current Opinion in Cell Biology 12 658-665.

Tanghe S, Van Soom A, Nauwynck H, Coryn M \& de Kruif A 2002 Minireview: functions of the cumulus oophorus during oocyte maturation, ovulation, and fertilization. Molecular Reproduction and Development 61 414-424.

Tilley DG \& Maurice DH 2002 Vascular smooth muscle cell phosphodiesterase (PDE) 3 and PDE4 activities and levels are regulated by cyclic AMP in vivo. Molecular Pharmacology 62 497-506.

Trounson A, Anderiesz C, Jones GM, Kausche A, Lolatgis N \& Wood C 1998 Oocyte maturation. Human Reproduction 13 52-62.

Urner F, Herrmann WL, Baulieu EE \& Schorderet-Slatkine S 1983 Inhibition of denuded mouse oocyte meiotic maturation by forskolin, an activator of adenylate cyclase. Endocrinology 113 1170-1172.

de Vant'ery C, Gavin AC, Vassalli JD \& Schorderet-Slatkine S 1996 An accumulation of p34cdc2 at the end of mouse oocyte growth correlates with the acquisition of meiotic competence. Developmental Biology 174 335-344.
Wang Z, Shi F, Jiang YQ, Lu LZ, Wang H, Watanabe G \& Taya K 2007 Changes of cyclic AMP levels and phosphodiesterase activities in the rat ovary. Journal of Reproduction and Development 53 717-725.

Webb RJ, Marshall F, Swann K \& Carroll J 2002 Follicle-stimulating hormone induces a gap junction-dependent dynamic change in [cAMP] and protein kinase a in mammalian oocytes. Developmental Biology 246 441-454.

Wu B, Ignotz G, Currie WB \& Yang X 1997 Dynamics of maturationpromoting factor and its constituent proteins during in vitro maturation of bovine oocytes. Biology of Reproduction 56 253-259.

Wu YG, Liu Y, Zhou P, Lan GC, Han D, Miao DQ \& Tan JH 2007 Selection of oocytes for in vitro maturation by brilliant cresyl blue staining: a study using the mouse model. Cell Research 17 722-731.

Received 29 October 2009

First decision 5 January 2010

Revised manuscript received 30 March 2010

Accepted 12 April 2010 